\title{
Commentary
}

\section{Smartphones Aren't Completely Evil: Why Smartphones Should Be Explored as a Form of Leisure Coping}

\author{
Christine Ausman ${ }^{1}$, CTRS \\ ${ }^{1}$ School of Health and Human Performance, Dalhousie University \\ Christine Ausman (D) http://orcid.org/0000-0003-3324-3423 \\ DOI: https://doi.org/10.15273/hpj.v1i2.10647
}

\begin{abstract}
While many post-secondary students experience mental health challenges in regular circumstances, the additional challenges posed by the COVID-19 pandemic intensify the need for mental health solutions. Leisure has previously been identified as a positive coping strategy among students as it leads to improved health and well-being. As many students' own smartphones, technology that can be used to access and experience different types of leisure, this suggests the possibility of using smartphones as a form of leisure coping. However, as smartphones are often considered to be detrimental to health, exploring the potential mental health benefits they could provide students has scarcely been explored. This approach to examining the possible positive impacts of smartphones on student mental health is guiding upcoming research in leisure studies at Dalhousie University.
\end{abstract}


Smartphones Aren't Completely Evil: Why Smartphones Should Be Explored as a Form of Leisure Coping

Post-secondary students are no strangers to mental health challenges, with $68.9 \%$ reporting overwhelming anxiety and $60.9 \%$ reporting more than average or tremendous stress in the last 12 months (American College Health Association, 2019). Coping strategies among these students can vary, although some are considered more adaptive when they lead to higher stress tolerance and increased resilience, such as participation in leisure (Denovan \& Macaskill, 2017). There are many definitions of leisure, and definitions have changed over time (Veal, 2019), but the term as used here refers to enjoyable activities participated in during one's free time (Kleiber, 1999). Leisure as a form of coping among students has been connected to improved health and well-being (Denovan \& Macaskill, 2017) and therefore highlights the importance of leisure participation among this population. In Canada, 97.9\% of internet users aged 15 to 24 years old own a smartphone (Statistics Canada, 2021). As smartphones have a variety of leisure purposes (e.g., streaming services, games, internet access, social media) alongside other uses, this presents an opportunity to explore smartphones as a tool for accessing leisure, and therefore, potentially as a tool used for leisure coping.

Although both the smartphone-leisure and leisure-health connections have been largely accepted, a gap remains in understanding the connection between smartphone-based leisure and its possible health benefits. One experimental study, examining the use of smartphones for coping, found that smartphones can act as a security blanket in times of stress by increasing an individual's resilience to stressful events (Panova \& Lleras, 2016). As smartphones can be used for coping (Panova \& Lleras, 2016) and also for leisure due to their many applications, it follows that students' use of smartphones may be considered leisure coping. In turn, if leisure coping leads to improved health, well-being, and resiliency (Denovan \& Macaskill, 2017), then it is possible the use of smartphones for leisure coping could provide some of these beneficial outcomes as well.

A study found that over $60 \%$ of Canadian adults increased their screen time in the early stages of the COVID-19 pandemic (Zajacova et al., 2020). In addition, the pandemic introduced a variety of other mental health challenges for students (Statistics Canada, 2020). These outcomes present additional reasons for researchers to examine the role smartphones can play in coping. Upcoming research currently underway at Dalhousie University aims to not only discover how smartphones are being used as a form of leisure coping among students, but how this person-technology relationship may have been impacted by the COVID-19 pandemic. Participants completed an online anonymous survey that included quantitative measures such as the Leisure Coping Beliefs Scale Short-Form and Leisure Coping Strategies Scale Short-Form, which were both modified to focus on smartphone-related leisure; the Immediate Adaptational Outcomes scale, measuring coping effectiveness; the Perceived Stress Scale; the Generalized Anxiety Disorder 7-item scale; and the Brief Resilience Scale. Qualitative questions were included to help contextualize the above measures. As students have a high prevalence of both smartphone ownership and mental health challenges, this population is best suited for research exploring the role of smartphones in leisure coping. This study will inform future research in coping, leisure, and smartphone literature to help better understand and contextualize post-secondary student use of smartphones within the context of health.

\section{Acknowledgements}

I thank Dr. Susan Hutchinson, Kimberley Woodford, Dr. Niki Kiepek, and Dr. Sara Kirk for their expertise and assistance in this research and its proposal. 


\section{References}

American College Health Association. (2019). American College Health AssociationNational College Health Assessment II: Canadian consortium executive summary, spring 2019. https://www.cacuss.ca/files/Research/ NCHA- II\%20SPRING\%202019\% 20CANADIAN\%20REFERENCE\%20GRO UP\%20EXECUTIVE\%20SUMMARY.pdf

Denovan, A., \& Macaskill, A. (2017). Stress, resilience and leisure coping among university students: Applying the broaden-and-build theory. Leisure Studies, 36(6), 852-865. https://doi.org/10.1080/02614367.20 16.1240220

Kleiber, D. A. (1999). Leisure experience and human development: A dialectical interpretation. Basic Books.

Panova, T., \& Lleras, A. (2016). Avoidance or boredom: Negative mental health outcomes associated with use of information and communication technologies depend on users' motivations. Computers in Human Behavior, 58, 249-258. https://doi.org/10.1016/j.chb.2015.12. 062

Statistics Canada. (2020, May 12). Impacts of the COVID-19 pandemic on postsecondary students. https://www150.statcan.gc.ca/n1/en/ daily-quotidien/200512/dq200512aeng.pdf?st=1HnsYrS-

Statistics Canada. (2021, June 22). Table 22-100115-01: Smartphone use and smartphone habits by gender and age group. https://doi.org/10.25318/ 2210011501-eng

Veal, A. J. (2019). Joffre Dumazedier and the definition of leisure. Loisir et Société / Society and Leisure, 42(2), 187-200. https://doi.org/10.1080/07053436.20 19.1625533
Zajacova, A., Jehn, A., Stackhouse, M., Denice, P., \& Ramos, H. (2020). Changes in health behaviours during early COVID-19 and socio-demographic disparities: A crosssectional analysis. Canadian Journal of Public Health, 111(6), 953-962. https://doi.org/10.17269/s41997-02000434-y 